Progress of Preventive Medicine.*

Ten years ago the only known means of preventing the invasion of exclude every person and thing contaminated by the germs of the disorder. In 1884 cholera was epidemic and severe in Egypt, and was soon transported to
Southern Europe. Germany, England, France, and Italy each appointed a commission of practical medical men and expert bacteriologists to inquire into the nature of the malady and devise means of prophylaxis. No better illustration of the rapid progress of preventive medicine and the manner of that progress can be desired than a study of the methods of investigation \begin{tabular}{l|l|l} 
pursued by those commissioners and the formulated & the film. Taking $v . g .15$ cub. mm. of turpentine, \\
results of their labors. Their investigations began in & the surface of the circle covered by the film will be
\end{tabular} Egypt. continued in Europe, and were complete in found to measure about $30 \mathrm{~cm}$. in diameter. Applyin India, where cholera has its continuous renewal and perpetual home. The results of their labors were not entirely harmonious at first, but the unequaled Koch, at the head of the German commission, made a detailed report of the work and established the facts, the accuracy of which has been conceded by all parties.

Accordingly, we now know that the cholera germ is the spirillum choleræ Asiaticx-commonly called the cornma bacillus of Koch-that it is found in the human body only in the intestines of its victims, where it multiplies rapidly; that it is not communicated directly from person to person, but the alvine evacuations of the victims find their way, generally through water, into the bowels of susceptible persons, who then become additional victims; that this germ also finds a breeding place in damp soil and in stagnant pools and in running streams containing organic matter, and survives i pure water, but does not multiply there; that is virile only within narrow thermal limits; that it holds its life by a frailer tenure than any other equally prolific and destructive pathogenic spirillum, being quickly destroyed by the official germicides, by drying, by acids, and by a temperature below $56^{\circ}$ or above $126^{\circ} \mathrm{F}$.

It is the application of this exact knowledge that has confined the cholera to the quarantine dominions at New York, thus preventing its diffusion in the United States ; and it is a like application of this knowledge that has, on sundry occasions and at divers points in England and on the Continent, enabled the authorities to confine the Asiatic plague to the single case in which it was discovered. And, per centra; it is ignoranee of these established facts, or failure to use them, that permits the ravages of cholera at this time in Arabia in Russia, and on the shores of the Mediterranean.

Every practitioner of medicine in this country should feel it an obligation to constitute himself a propagandist of the knowledge of the means of prevention of cholera among the populace, and when the people are thoroughly informed in this behalf and join intelligently and beartily with the health authorities in recognizing and managing the first case that may atpear in any locality, the disease will be stamped out at that point, and then cholera can never again become epidemic in the United States.

YELLOW FEVER.

Yellow fever is another scourge that has been and still is being much studied, and not with such satisfactory results touching the nature of its course as with cholera, but enough has been deterinined in regard to its nature to warrant the declaration that it can be stamped out at any point where it may appear. All that is necessary to protect us from further invasion of yellow fever is the watchfulness, the intelligence, the skill, and the devotion to duty everywhere that has beeil so successfully exercised for eight years by the health authorities at New Orleans.

It is known that yellow fever is an exotic in the United States, and that it comes to us almost exclusively from the inter-tropical islands and mainland on the eastern border of the Western Hemisphere, and it is a reasonable anticipation that the diligent expert investigation now actively prosecuted will presently yield us such knowledge of the nature of its germ and its nativity as will enable us to strangle it in the place of its birth. The pregnant idea of dealing with germ diseases, that have a localizer! origin, at the point of their generation was under consideration by the PanAmerican Medical Congress at its first session in Wash ington in September, and it is just such great organizations as that, composed of men with enlightened minds and courageous natures, that will work out the problems of sanitary science and art for the welfare of the world.-Jour. Amer. Med. Assn.

The American Teredo Proof Company has erected works at Gig Harbor, Puget Sound, where piling for wharf and dock building is treated with a patent preparation, after which, it is claimed, they will withstand all attacks by the destroying teredo.

* Abstract of Address on General Medicine, at a
sippi Valley Medical Acsociation, October 12, 1808.

\section{INTERESTING EXPERIMENTS.}

BX PRor. F. J. Bruto. cumference of a large circle, which it clears perfectly f any trace of the powder. Besides illustrating the ehavior of the film toward the lycopodium, the exEXPERIMENT IN GRAVITY. sylindrical pieces of wood, as shown in Figs. 1 and 2, to make a double wheel. Then procure two rails about wo feet long, with a projecting part in the middle, a eross section, Figs. 1 and 2. The projection of Fig. will be noticed to be longer than that of Fig. 2, and the distance from the axle to the rims of the wheels to be less than projeetion in Fig. 1 and more than that in Fig. 2. Now putthe two rails with their ends close together, supporting the opposite ends, to for use. Set the wheel on upper end of rail No. 1 . Since the projection is greater than the corresponding groove of the wheel, the latter will roll down on its inner cylinder, producing a very slow run, but a certain
momentum will be developed which, as soon as the momentum will be developed which, as soon as the
wheel strikes rail No. 2, will change the rate of velocity to a much higher degree, because on the second rail the wheel runs on its outer cylinders. Thus you have wheel running faster up hill than down.

As will be understood, the projection of rail No. 2 is used only to deceive the eye.

III. A'n Optical Nlusion-Between the electrodes a Holtz-Toeppler machine place an electrical whirl

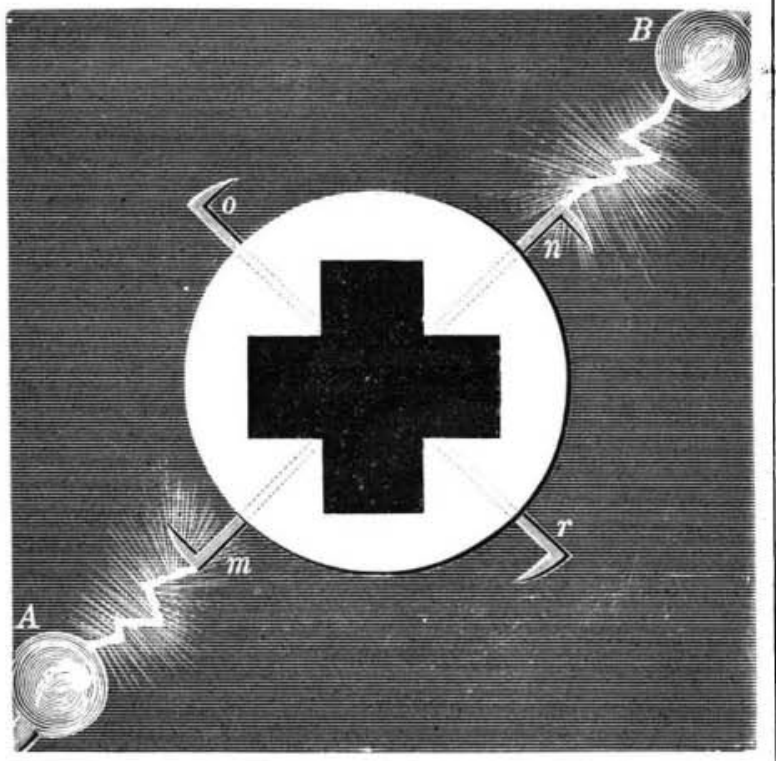

AN OPTICAL ILLUSION

the dark will show the cross always in the same position, thus giving the whirl the
rest, though it mcres rapidly. I. Experiment with Turpentine Film on Water.- in beet cultivation by planting and subsequently diameter with lycopodium. Put in the middle of the by accurate calculation that nitrogen may be thus furpart covered a drop of turpentine. A very striking nished to the soil at lower cost than is possible eithe action ensues. The turpentine sweeps in a moment by the use of barn-yard manure or through chemical the lycopodium from the center away toward the cir- salts, such as sodic-nitrate, etc. About 20 tons of beets, x- A mode of working beet sirups for second and third periment shows the velocity with which such a film gradesugars has been giving some success. Immediatereads over the surface of water, and finally may ly after the sirups leave the pan, while still hot, air is forced through them. After twenty-four hours there forms a voluminous frothy mass, which has a specifie gravity less than water. If this is allowed to remain crystallizing tanks, nearly all the sugar of the sugar offers no special novelty; it is interesting sugar th this process averapes a very low percentage of ash. The tanks used for mixing the air with sirups are made very much after the plan of those used in saturation of beet juices with carbonic acid. The air may be either forced through or drawn through: the time required depends upon the quality of the produet worked.

Recent experiments show that electricity has one effect upon beet juices that is not to be overlooked. The sugar percentage increases, but this is followed by a slight decolorization. About 50 per cent less time in such cases is needed for defecation than by ordinary methods of carbonatation. When zine is used as an electrode, the metal is dissolved; one portion the formula of the cylinder's volume: $\mathbf{V}=r^{2} \pi h$ the of it becomes a neutral double salt and the other portion a zincate, which gives an alkaline reaction to the juice.

When platinum is used as an electrode, inverted sugar is formed; this is never to be dreaded with zinc. Other experiments upon diff usion juices, with an electric cur11. Experiment in Gravity. - Fit together thre $\begin{aligned} & \text { rent from a Siemens dynamo giving } 35 \text { to } 40 \text { amperes } \\ & \text { with } 4 \text { to } 5 \text { volts between the zinc electrodes, resulted }\end{aligned}$

in a deposition on the positive pole of a thick, fatty substa ice. This should be withdrawn before the juices are defecated with lime. The electric cument coagulates the albumen to a certain extent. While certain ex planations may be offered as to the reactions, etc., that take place, none are sufflciently accurate to be generally accepted.

The sugar manufacturers have declined to accept the picposal of the sugar refiners respecting raw sugars of $88^{\circ}$. Special arrangements have been made as regards sugars testing $92^{\circ}$. The latter are almost free from organic substances. It has been recommended that considerably more of the $88^{\circ}$ sugar be made than hitherto under such circumstances the manufacturers may be better able to make terms with the refiners.

The problem of handling waste waters from beet sugar factories is by no means settled. The water residuum, most to be dreaded, comes from the diffusion battery and pulp presses. In some special cases, where there is a scarcity of water, this waste water must be used over again. Notwithstanding the precaution of purification, such as employed, after a reasonable time the salts, etc. , not eliminated give considerable trouble during manufacture.

The experiments made in crystallization in motion appear to continue in favor among manufacturers, most of whom are willing to admit that by this plan more sugar may be extracted from second and third grade sirups than by any other existing method.

Some most interesting experiments have been made to determine the loss of sugar during evaporation of alkaline juices. After 90 minutes a solution containing 250 grammes sugar, 20 c.c. potassic solution, 230 grammes water, heated to $125^{\circ} \mathrm{C}$., polarized $49 \cdot 11$, corresponding to a loss of 0.74 in the polarization. All experiments appear to point to the fact that alkalinity resulting from existing methods of working has but little influence on sugar destruction; what changes do occur may be mainly attributed to heating.

Exportation of beet sugar from Hamburg has remain ed almost stationary during the past four years. Dur ing 1892-93 it was 653,722 tons, of which England received 242,515 tons refined sugar.

Slices of cork have been giving most excellent results in filter presses; these obviate many of the difficulties contended with in filtering very dense sirups. The expense is about $\$ 10$ per 10,000 tons beets. The cork offers an excellent medium for several days withou being renewed; in fact, even then it may be washed at the same level with the electrodes. To the whirl in the presses, which operation demands about oneyou fasten a circular piece of stiff white paper with half hour. The cork may remain in the presses for a some regular figure on it in black. The pivot on month, provided it receives its regular washing at which the whirl is to rotate should be insulated. After intervals of one week. The filling and emptying cork a few seconds of running your machine, sparks will requires less time than the renewing of filtering cloths. pass over every time when the wire, $m$ n or $o p$, takes Any bone filter may be changed into a cork filter.- The the direction of A B. This experiment performed in Sugar Beet.
ThE first coast light. in the United States was erected in 1678 . 
A Wire Tramway in the Alps.*

A wire tramway having some very long spans has recently been built by Bullivant \& Co., of London, from the designs of Mr. W. T. H. Carrington. This tramway has been built to carry talc from mines at a high level in the Italian Alps, on the Franco-Italian
frontier, near Pinerolo, for Brayda \& Co., of Turin frontier, near Pinerolo, for Brayda \& Co., of Turin. above the sea, and the material has to be carried to a road situated at a level of about 2,500 feet above the sea, whence it is carted to the railway station at Pine-
rolo. The mines occur at various points along the line rolo. The mines occur at various points along the line in the rear of the same. This mode of tightening is
of tramway, and the quantity transported per day is found most convenient, as it admits of the fixed rope about forty tons. The return trafic up the tramway being slacked out on to the ground for examination at consists of military stores required for the use of the
fortresses erected for the defense of the Italian frontier at various points along the mountain range. The wire tramway erected consists of one upper span, having a length on the incline of 3,090 feet, with a gradient of 1 in 4. A length of ground tramway proceeds from the lower end of this section, by which the material is collected from various mines situated on the lower plateau, and over which the material brought down
by the upper section is transported to the upper terminal of the second incline. The latter ropeway is 4,200 feet on its inclined length, and has a gradient of 1 in $21 / 2$. From the lower end of this the third incline extends to the roadway above named, the length of this lower incline being, on its inclined length, 3,600 feet with a gradient of 1 in 2 . The nature of ground traversed by this latter incline necessitates the use of a support on a ridge about one-third of the distance
from its upper terminal, and at this point the fixed ropes are supported in suitable saddles. over which the carriers run, and the hauling ropes are carried on suitable guide wheels. The upper portion of this lower incline, thus divided by this support, has an incline of

of 1 in $13 / 4$.

All these inclines are constructed on the principle adopted on many other lines of a similar character: two fixed ropes are stretched from end to end of the incline, and an endless hauling rope is employed, which, at the upper end, passes round a suitably devised brake gear, while at the lower end it is passed
round a tension pulley, by means of which suitable round a tension pulley,
strain is put on this rope.

* A bstract of article in the London Engincer.

The carriers are designed to contain about $600 \mathrm{lb}$. of $\mid$ the empty carrier up. When it is not required to transThe running heads from which they are suspended, stones, etc., by means of which the military stores are and by means of which they run on the fixed ropes, are transported up the mountain. It is found that with provided with steel wheels carried in a wrought iron $600 \mathrm{lb}$. of mineral in the-descending carrier about 250 rame in which the hanger of the carrier pivots and lb. of military stores can be brought up in the ascend moves freely. The attachment of the hauling rope is ing bucket.

made to the head by means of suitable pendants, to re tightened by means of blocks fitted with Bullivant's patent flexible steel wire rope, and a crab winch placed in the rear of the same. This mode of tightening is

The great length of the second span will be noted; it weight of about $1,150 \mathrm{lb}$. The fixed cables are composed of specially made steel wire rope having a breaking of special character to suit the requirements of this description of work. Great care is taken in the attachment of these ropes at the ends, where thes are held by ing, and by means of which the rope is not weakened at the point of attachment. The carriers are allowed to travel at a speed of about 35 miles per hour. The
whole section is controlled by one brakeman, who, when not employed in controlling the running of the line, is occupied in loading the carriers, etc

The transport of the materials discharged at the lower end of the middle section to the upper terminal of
the lower section is performed by small trucks which run on a short line of railway between the two points. With the small quantity of mineral required to be carried, the use of this arrangement involves no extra labor; where, however, it is necessary, a direct inter-
change of loads from one bucket to another can be change of loads from one bucket to another can be to be carried is very considerable. The support placed in the lower incline consists of a timber frame of ample strength, between the upr: ${ }^{-h}$ ts of which is suspended a steel transom carrying saddles on which the fixed ropes rest, and between these same uprights, at a lower point, will also be seen the wheels with their guide bars arranged for carrying the hauling rope, by mean
of which the loaded carrier when descending bring
Injurious Photographic Chemicals.

The British Journal says : Metol seems to be gaining, rightly or wrongly, an unenviable character for the injurious action it is said to exercise on the hands fits users. But, be it.ever so hurtful, is there any eason why it should be allowed to exert, its ill effects ? In the development of negatives, only the extreme tips of the forefingers and thumbs need be wet with the soling injurious chemicals, it is only when they come in contact with the thinner portions of the skin-as on the perfectly protect the fingers from all pernicious materials. They are much more extensively used by phothraphers,'both professional and amateur, on the Conhey are by no means uncomfortable to work in. It is urious to note the effect that different chemicals have n different persons. One gentleman we knew, who for years had been dealing with impunity with cyanide of potassium in connection with electroplating as well as photography, suffered severely from bichromate of potash. Another gentleman, on whom the bichromate
was innocuous, even when used on a large scale, could scarcely touch cyanide withou tsuffering inconvenience. Even the smell of it created nausea and headache. In the wet-collodion days, a friend of ours had to relinquish photography, so far as the development of his negatives was concerned, on account of the injurious the iron solution had upon his hands.

Underground, Conduits in New York city.

The underground electrical conduits in New York City have now a length of 1,667 miles. In these conduits there are about 32,600 miles of telephone and teleposes, with which about 6,790 arc lights and 268,000 incandescent lamps are connected. lution, and then only the front portion of them, where contact with the thinner portions of the skin-as on the
back or bet ween the fingers-that any harm results. However, India-rubber finger stalls, costing but a few pence each, are to be had at all rubber shops, that will graph wires and 1,300 miles of wires for lighting pur-
RECENTLY PATENTED INVENTIONS. Engineertag.

Engine Governor.-William H. Watson, New Orleans, La. According to this invention the
steam passes through the governor on its way to the ensteam passes through the governor on its way to the en-
gine, and the speed of the engine is thus regulated to a gine, and the speed of the engine is thus regulated to a
nicety without using any gearing or exterior mechanism. The governor comprises a casing, having an inlet at one held in the outlet end, while there is a central chamber through which slides a piston having end chambers with ports leading to the central chamber. The regulating
piston 18 moved back and forth automatically by the shifting steam pressure.

\section{Rajlway A ppliances.}

Car Coupling.-William F. White, Chicago, $\mathrm{nl}$. This is an improvement in knuckles of the Janney type, and consists principally of a pivoted tension adapted to be engaged by the forked end of the coupling pin. The extension has a beveled portion, and
its front and rear edges are adapted to be engaged by two parallel prongs of the pin, the rearmost of the prongs having a lug engaging the beveled portion of the exten-
sion, while a lug in the drawhead is adapted to be engaged by the pin to impart a swinging motion to the latgaged by the pin to impart

air Brake Coupling Device. Charles F. Bane, Lafayette, Ind. The hose coupling according to this invention, has two movable interlocking valve within each section, there being on the stem of each valve an arm having limited movement between the stop
lugs of its own section and adapted to be engaged by the lng on the section carrying the other valve, to be moved
against one of the stop lugs of its own section. The dethe couplings whenever the coupling members are united, thus form
ing an uninterrupted passage for the air in the train pipe ing an uninterrup

Axle Box Lubricator. - James S. Patten, Baltimore, Md. This is an improvement on a
former patent of the same inventor, according to which former patent of the same inventor, according to which
there is inserted and held in the car axle box proper a box containing a liquid lubricant, with means for taking up the lubricant and transferring it to the journal ; al
for recouvering into the box any surplus which may ac cumulate on the joornal. The improvement having be practically adopted by several railrood companias, the
inventor has devised and covers in this patent a better working for mod and use on railroad cars in ordinary service.

\section{Electrical.}

Electrical Resistances. - George B. Lawrason, New Orleans, La. An instrument for measur-
ing and regulating these resistances, on the principle of the Wheatstone bridge, has been devised by this inventor. a rotatable non-conducting cylinder, the adjustmen shortening or lengthening the distances between the
point bridged from the main oirveit, and a condicting point bridged from the main oirseit, and a condicting ranged parallel of with the cylinder and adapted to rotate 'Ihe conductors wound in the grooves of the cylinde
are also looped around the rod, so that the current is no are also looped around the rod, so that the current is ce may be varied at will by rotating the cylinder.

Railway Signaling apparatus.Edgar C. Wiley, Bristol, Tenn. The principle employed this invention comprises a series of electro-magnets
he roadbed or along the line and energized through contacts made mechanically by the passage of the train
these magnets acting by induction upon magnets carried these magnets acting by induction upon magnets carried
by the locomotive, which pass the stationary magnets so closely as to induce in the magnets of the locomotive
current strong enough to close a local bell circuit on th train and sound the signal, thus apprisingthe engineer of any train of the

Series Electric Railway.-Michel Angelo Cattori, Rome, Italy. The conductor, according to thisinvention, consists of hed separated and insulated breakers in the gape between sections, to beisoperated by the locomotives to open or close the gaps, while four conducting wires connect the generating machine with the
conductor in sets of two at two separate points, the conductor being interrupted between the two wires of each
set, and there being means for electrically connecting th wes of the machine with either of the sets of conductfeatures for an improved series system electrical railway with underground conduit.
weatures for an improved se

\section{Mechanical.}

NuT Lock.-John W. Schoaf, McKees port, Pa. This is an Improvement in nut locks, employ-
ing a spring washer formed of a spring-split ring, with ends projecting in opposite directions to act as pawl
and the invention consists in fitting a guard plate ove the spring washer, so that the washer may be partly com pressed, but cannot be mashed flat and so be damaged ration of the spring washe:

Combination Tool. -Riley L. Davis, Asheville, N. C. This tool has a hammer or socket head,
to which is secured a cutting or clipping tool, and to the latter is detachably secured a supplemental tool for cut-
ting wire, or for use as a screw driver or wrench. The ting wire, or for use as a screw driver or wrench. The
handle of the hammer head is so secured in a tapered handle of the hammer head is so secured in a tapered
socket that shrinkage or wear of the handle may be Saw Mill Feed Mechanism.-William Fleming, Athens, Ga. This is a variable feed de vice, comprising a pivoted rotary shaft and shiftable fric
tion disk mounted on a sliding sleeve, to which is pivored a hand lever. By moving the lever in either of two di-
rections at right angles to each other, the log carrage i rections, at right angles to each other, the log carrlage wheel longitwdinally on the shaft the epeed of the car-
riage is regulated.
Treadle Attachment,-Andrew Prader, Spokane, Wash: This is a smple attachment de-
signed to prevent dead center positions, so that the driven thaft is rotated in a forward direction on starting the. pitman and treadle as to exert pressure against the uppe end of the pitman, and consequently on the wrist pin, to
hold the latter out of a dead center position relatively to the treadle whenever the machine is stopped.

Agricultural.

Weed Cutrer.-Robert H. Douglass, Colville, Wash. This machne has main cutters of $\mathbf{V}$ ing edges, the angle of the cutters being at the rear, and in conjunction therewith are upright cuttere and mean
whereby the cutters may be quickly and easily adjusted whereby the cutters may be quickly and easily adjusted
to cover more or less ground, or adapt themselves to rows to cover more or less ground, or adapt themselves to rows
of different widths. The machine is of very simple, of different widths. The machin
strong and inexpensive construction.

Miscellaneous.
Ventilation OF BUildings.-William M. Decker, Kingston, N. Y.' This inver:tor has devised a special method of construction in which atr shapts lead
from the cellar to outlets at the top of the building, com from the cellar to outlets at the top of the building, com-
municating wirh spaces under each floor, while pipes means for inducing an upward flow of air ; there are also air spaces in the several walls of the building, and lateral openings leading from the floor spaces to the wall
spaces, and from the latter to the air shafts. The construction affords means for accurately controlling the heat
supplied to different rooms, and effectively removing the foul air. Grip Testing Machine - Theobald E. J. Schaibly and Walter Schaibly, Philadelphia, Pa. by on of these inventors, simplifying the construction,
and pro iding means for connecting the tension spring and pro iding means for connecting the tension springs
directly to the handle levers and the sides of the case. directly to the handle levers and the sides of the case.
There is also a connection between the levers and a There is also a connection between the levers and a
registering mechanism thrown into gear by dropping a coin into a chute of the machine, the levers being throw
out of gear as soon as they are started, so that they out of gear as soon as they are started, so that they can-
not again operate the registering mechanism until an not again operate the registering mechanism until an
other coin is dropped. A brake mechanism holds the other coin is dropped. A brake mechanism mochanism
indicating hand at the point it reasches, the meras
befng released and the hand returned to normal position on pressing a button.

Folding Bedstead. - Paul Gustave Le Dan, Paris, France. This bedstead is intended primanly for use by officers on campaign, explorers, and
others. The side pieces are each formed of two sections hinged together, the foot piece being detachably cornected and carrying a foot at each end, while there are
feet hinged to the head sections of the side pieces, and an adjastable and hinged back. These bedsteads are
preferably made of copper tubes, to weigh only about ten pounds, and have a novel style of coupling and fitting
whereby they may almost immediately be transformed whereby they may almost immediately be
into a long chasin, an easy chair, or a atool.

Wire Fence Gate. - William W. Halladay, Farina, II. This gate forms really 0 only a part
of the fence, and is so cheap and simple that it may be of the fence, and is so cheap and simple that it may be
applied at frequent intervals between the posts of the fence to afford openings at any desired point. To the free ends of the strands of a fence section is fastened a stile whose lower end is held to a post by a common
staple, while near the upper end of the stile is a link engaged by a hook extending through a hole in the post,
the back of the hook being pivoted to a cam lever. the back of the hook being pivoted to a cam lever.
When the gate is opened the stile and wires are carried to one side, or the wires may be rolled on the stile. Wire Stretcher.- William P. Negus, West Branch, Iowa. This is a simple device especially
adapted for stretching any kind of woven wire fencing, Wapted for stretching any kind of woven wire fencing,
working equally well with batped or smooth wire, and adjusting itself to any size of wire. It is a forked lever whose prongs have inclined ênds, a dog being pivoted whose prongs have inclined enda, a dog being pivoted
between them and having shoulders adapted to swing opposite the inclined endis of the prongs, while there is a
toothed cross pleee on the free end of the dog. The device is strong and durable, holding the wire very firmly. is is also useful in repairing old, loose fences, as well as WEather STRIP.-Norman N, Hazel-
Wetching new fence. ton, Lamoni, Towa. This strip comprises a spring plate
secured to the outer face of the door, its lower eud riding on the threshold piece, while a catch member has a hank portion passing through the door and engaging the and inexpensive, but is designed to effectively exclude and inexpensive, but is designed to effectively exclude T or bumper to protect the wall and wall paper.
T A V L I N G C A S E. - Florence Leonard, Arlington, Ga. This is a case designed to be
especially useful for ladies as well as gentlemen for
short trips, and has apartments to properly contain

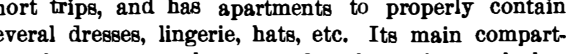
ment is preferably about two feet long, sixteen inches
wide and nine inches high, and hinged thereto is a top wide and nine inches high, and hinged thereto is a top
section on which are hat boxes, the case also having the INHALER-Alfred M. Adsit, Hastings, Minn. This is a device for the administering of anæs-
thetics, and has a hollow body with top air inlet, a liquid reser oir and liquid discharge regulator, and a series of 